\title{
Prehistory in the Interdisciplinary Discourse of A. Chechelnitsky: Implementation of Scientific Principles and Ethics
}

\author{
Irina Alekseevna Gataullina*, Olga Mikhailovna Gilmutdinova, Natalia Mikhailovna \\ Topal
}

Kazan national research technical University named after A.N. Tupolev, Kazan, Russia

* Corresponding author. Email: gataullina.irina2010@yandex.ru

\begin{abstract}
The far Eastern version of the prehistory of mankind by astrophysicist A. Chechelnitsky is considered as a model of implementation of an interdisciplinary approach in the study of the past, which left no physical evidence. The contradictory evidence from ancient sources revealed by the scientist and their comparison with both biblical data and data from modern branches of knowledge and common-sense logic are justified as weighty arguments in favor of an alternative picture of the origin of history. It is argued that the concept of A. Chechelnitsky is aimed at overcoming the vices of modern thinking, reductionism and fragmentation of knowledge, in favor of methodological universalism, when the integration of cognitive methods provides a truly scientific search that reflects the moral position of the scientist.
\end{abstract}

Keywords: scientism, methodology, "universal history”, A. Chechelnitsky, Prehistory, Displaced geography, Transferred toponyms

\section{INTRODUCTION}

I. Savelyeva in her work devoted to comprehending the prospects for the development of historical science in the 21 st century on the basis of a detailed analysis of the state of humanities and the degree of its sociologization since the middle of the 20th century, gives a reference to the work of D. Christian. "We will see the return of the ancient tradition of "universal history" in the next 50 years; but it will be a new form of universal history, global in practice and scientific in spirit and method, up to the possible integration of historical humanities with historically oriented natural sciences, including cosmology, geology and biology" $[1,2]$. This prediction seems to be extremely important, since never before have professional historians come close to the idea of integrating cognitive methods as they do today; this allows us to raise the question not of the next turn in science, but of a real revolution in it. Astrophysicist A. Chechelnitsky built a methodological construct for a new form of universal history using non-trivial ways to solve a number of historical problems.

We dare to assume that the name of Albert Mikhailovich Chechelnitsky is unknown in the humanitarian sphere of knowledge. It seems that it is hardly making its way in the domestic physical and astronomical academic environment. He is called a marginal scientist whose views do not fit into the established canons of conventional science [3]. This is probably why information about the scientist is not in the universal Internet encyclopedia Wikipedia, positioning itself as a public resource with free content. The electronic Russian encyclopedia Tradition very succinctly reports on A. Chechelnitsky. A certificate of a famous specialist in space research, theoretical physics, cosmology, constructive sociology, anthropology is available only on the website of the library system of Dubna State University, to the Joint Institute for Nuclear Research where the astrophysicist worked. It also contains information about a personal library that he collected throughout his life and donated to the university, containing 1106 books from various fields of knowledge, including philosophy, linguistics, and history. Despite the scarcity of information, it is clear that the views and interests of the scientist were formed in the Soviet era and during the "unthinkable before (and after) scientization of history based on the structural-functional analysis and systems approach" according to the chronotope of world historical science I. Savelyeva [2]. If the historical branch of knowledge has undergone such training, then, following A. Cont-Sponville [4], it can be argued that science in those conditions could really be compared only with religion. The pejorative connotations of the concept of "scientism" that arose and continues to arise in this 
connection turned out to be too strong and tenacious to be considered as a product of only the 60-70s of the 20th century. In these circumstances, the position of astrophysicist A. Chechelnitsky, who managed not to succumb to the charm of absolutizing scientific knowledge of the worldview, as well as the danger of challenging it, deserves special attention. It is an expression of genuine scientific universalism as a result of the inquisitiveness of the mind and doubt, providing movement to the truth.

There are two historical works in the full sense of the site on the library system of the Dubna University of 81 publications by a scientist [5], most of which are devoted to the study of the Earth, the Universe, the Solar System and Wave Astrodynamics [6, 7]. The amazing thing is that, studying the problems of astrophysics, A. Chechelnitsky projects the results of his research on the historical process in time and space, touching on the problem of its source - Prehistory. It is permissible to ask the question: to whom and why is this needed? After all, there are well-established and accepted by modern people ideas about the past of mankind, which there is no need to revise.

Numerous mysteries of ancient human history today are in the focus of close attention of world science, regularly reporting on its results. Thus, the amendment of Rob van der Voo, a professor at the University of Michigan, and Trond Torswicka, a Norwegian scientist, models the prehistorically unified mainland Pangea, which broke up 200 million years ago [8]. The sensational findings of Russian archaeologists in 2010 in the Altai Territory of the remains of Homo sapiens althaiensis, the so-called Denisovsky man, along with the taxa Homo sapiens africanensis (in Africa), Homo sapiens neanderthalensis (in Europe) and Homo sapiens orienthalensis (east) mainstream supporters of the polycentric concept of the formation of a person of a modern form [9]. Moreover, the results of a study of the remains of Homo sapiens found on the Atlantic coast in Morocco, which are 315 thousand years old, shift the time of the origin of Homo sapiens 100 thousand years ago [10]. Recent genetic studies of the remains found in Alaska, carried out by a group of scientists led by Eske Willerslev, continue to develop confirming the Beringian Stagnation Model, according to which Asian immigrants traveling to North America from 15 to 25 thousand years ago were really delayed and genetically isolated Beringia, a paleographic area that has now gone under water [11-14]. Samples collected during the 63rd Russian Antarctic expedition, samples of the oldest ice on the planet, whose age is possibly more than 1.3 million years, are of tremendous importance for historical science. Scientists claim that since such ice contains the ancient air of the Earth, so far it can tell about the climatic mysteries of the past planet and we can look for traces of events in it. The so-called Middle Pleistocene climate revolution that occurred on Earth about a million years ago led to an increase in the length of the "glaciation - interglacial" climatic cycles from 40 to 100 thousand years, due to changes in the concentration of carbon dioxide in the atmosphere. The dating is confirmed by independent methods based on measuring the concentration of cosmogenic isotopes in ice [15]. The study of nearly one and a half million ice cores by age allows us not only to identify the causes and mechanisms of climatic variability over the past 2 thousand years, but also significantly change the angle of view on the event picture of the world. This means that the past is a reality that corrects the knowledge accumulated over centuries by knowledge, which, as the above facts testify, is far from being considered complete and consistent. Here, the scientific community faces the question of professional competence, expressed not by a set of established knowledge, but by how this knowledge relates to the challenges of the time and is resolved in the paradigm of dense information with its central leitmotif "How was it really?". The crisis of self-identification is the central question of the seeking scientist: the search for truth inevitably leads him to the value choice of truth or falsehood in science. If the first is building a strategy of constant movement towards the truth, then the second is a dead end. The concept and methodological construct of A. Chechelnitsky reflect the deeply moral position of the scientist who believed that "no solid building, both in life and in science and in society - from physical theories to great conceptual or social systems - cannot be built on an inappropriate basis" [7]. The purpose of the article is to present a set of alternative ideas of a scientist as a methodological basis of relevant historical research.

\section{METHODS}

This article is built on the basis of a review of the scientist's methodological approaches, using the example of a prehistoric problematic to make it necessary: a) to use non-standard research techniques; b) promoting interdisciplinary research; c) understanding the importance of universalism as an indicator of a holistic culture and worldview solvency of a scientist. All this focuses on rethinking the role and ethical image of the researcher, who, learning to build a dialogue with the past, makes himself a "vaccine against violence" in the present.

\section{CONCEPT HEADINGS}

The central idea of the works of A. Chechelnitsky is a critical rethinking of the current notions of ancient history as a field of knowledge about the past of mankind. The scientist claims that this story, created from written sources, contains a lot of conflicting information, casting doubt not only on the competence of ancient authors - the main informants of antiquity, but on the awareness, first of all, of modern scholars who still operate on information that has not been subjected to critical analysis. Paraphrasing the outstanding Sumerologist S. Kramer, 
who had good reason to consider the Middle East Sumer not only the first civilization on Earth [16], but also the beginning of history [17], A. Chechelnitsky put forward his version, according to which "the history of the Sumerians begins in the Far East" [7]. It seems that this thesis cannot leave indifferent either the bearer of ordinary knowledge or a specialist historian. In this case, it is difficult to get rid of the feeling of professional inferiority: after all, all historians are familiar with the works of ancient authors, but astrophysicist A. Chechelnitsky managed to identify a lot of conflicting information in them. For the first time he was declared this in a study on the problem of Atlantis [6]. The scientist presented arguments against a stable opinion about the localization of an ancient island outside the Mediterranean Sea as well as that of the Atlantic Ocean, proposing the idea of finding its sources in the Alaska region, substantiating the identity of the concepts of the Bering Strait and the Hercules (Heracles) or the Melkart Pillars [7].

The theme of Atlantis, as well as Hyperborea - mythical island-states - brought the scientist to the problem of the Prehistory of mankind, in the study of which he was one of the first to turn to the Bible as a historical source, which, according to the scientist, deserves the attention of researchers no less than antique works. At the same time, Chechelnitsky relies precisely on the synodal translation of scripture, since all others convey a free interpretation of the text, leading to semantic distortions. The synodal translation of "The Revelation of St. John the Evangelist" conveys the catastrophe of the city of Babylon, which, according to the description, is similar to the seismic one [18] and might not have happened in the flat valley of the Tigris and Euphrates [7], and in the Asian region. Having discovered the discrepancy between the biblical and later hydronyms and ethnonyms in the works of ancient authorities, the astrophysicist raised the question of Transferred place names and Real geography. So, India, washed by the Atlantic Sea or the ocean [7], perhaps the most paradoxical thesis of Strabo. Recognizing the inconsistency of the information of everyone who helped Alexander of Macedon to conquer Asia, had ever seen this country or heard about it, [19], the scientist and author of "Geography" considered the most reliable short story of Eratosthenes about the land, which was considered in his time India. "India from the north is separated in space from Ariana to the East Sea by the very extreme parts of the Taurus, which the locals give in parts the names Paropamis, Emod, Imai and others, and the Macedonians the Caucasus. In the west, the border of India is the Indus River. The southern and eastern sides are much larger than the others and protrude into the Atlantic Sea" [19]. According to the fair remark of A. Chechelnitsky, from the point of view of modern geography it is reasonable to ask the question: how does India relate to the Caucasus, the East Sea and the Atlantic Ocean? What kind of India are we talking about? The same confusion arises when determining the location of Hyperborea. Hekatei Abdersky, a follower of Democritus, in a fragment of his lost work "On Hyperboreans", indicated that the path to the Hyperborean island located in the ocean passed through Meotida and the mouth of Tanais - toponyms interpreted by modern science as the Don River and Sea of Azov [19]. However, in which ocean was the island of Hyperboreans? [7].

Excavations of Babylon, begun, but incomplete by German archaeologists led by R. Koldevei at the turn of the 19th-20th centuries, is another object of critical analysis of astrophysicist. Chechelnitsky questions the version of the completion of excavations of the city - the capital of the empire of the 2nd millennium BC due to the high level of groundwater, hypothesizing the complete futility of archaeological work due to the lack of cultural layers of the Hammurabi era [7]. The scientist does not agree with the position of the Danish archaeologist J. Bibby, at the suggestion of his British colleague and assyriologist G. Rawlinson, who believes that the "forgotten" ancient Eastern civilization is the mysterious country of Dilmun - the island of Bahrain in the Persian Gulf [7, 20]. Analyzing the contents of the evidence of Sargon of Akkad from Khorsabad inscriptions, Chechelnitsky claims that Dilmun (Tilmun - red. A. Chechelnitsky) is not an island, but a peninsula connected with Kamchatka, which was largely a mountainous country [7]. Having a port and part of the land border, Tilmun was the Great Path of copper transit. The astrophysicist claims that the main strategic commodity of antiquity came from the coast of the Sea of Okhotsk, from Magan (Makan - ed. A. Chechelnitsky), which was most likely Magadan, one of the richest regions in the world for mining. According to the scientist, Melukhu (Meluku - ed. A. Chechelnitsky), the "black mountain", which S. Kramer attributed to Ethiopia (Numibia), must be sought in the same place $[8,9]$.

In all three cases, speaking of Dilmun, Magan, and Melukh, Chechelnitsky applies an analysis of constructive paleolinguistics (hereinafter $\mathrm{CP}$ ) by constructing a consonant matrix (hereinafter referred to as $\mathrm{CM}$ ) or a consonant root (hereinafter CR) of words, composing an associative cluster (hereinafter $\mathrm{AC}$ ), revealing characteristic signs of their localization [7]. So, the word Melukhha (Meluka) has CM in the form -M-L-K-, which is the basis of many words and concepts that form AC. Paleolinguistic analysis in this case is important for detecting traces, both in memory and on the ground, through the so-called symptomatic toponyms. For example, the city of Malkachan, which exists to date on the coast of the Sea of Okhotsk, and a little to the north of it is a mountain with a height mark of $1448 \mathrm{~m}$, behind which ridge there is access to the Kolyma River with its storehouse of gold, silver, tin and copper. A. Chechelnitsky shows that gold - silver transit in this area was quite real, and the consonant root - M-L-K - both in Malkachan and in Melukha proves the symptomatology of toponyms [7]. No less surprising are the arguments about the toponym Aratta, when, based on CP analysis, the scientist not only indicates the location of Aratta in 
Northeast Asia, but also connects this toponym with the Golden Horde based on the KM term Horde -RD-, -RT(Golden) Aratta - (Golden) Arta - Golden Horde [7]. Appealing to the Bible, A. Chechelnitsky claims that Babylon is also not a Mesopotamian concept, and cites a well-known, but read in a new way, really important fragment of it:

" 1 . There was one language and one dialect on the whole earth. 2. Moving from the East, they found a plain in the land of Senaar and settled there. 3. They said to each other: we will make bricks and burn them with fire. And they had bricks instead of stones, and earthen resin instead of lime. 4. They said: we will build for ourselves a city and a tower high to the skies, and we will make a name for ourselves before we scatter over the face of the whole earth. 5. The Lord came down to see the city and the tower, which the sons of man built. 6. The Lord said: behold, there is one people, and one has one tongue; and that's what they started to do, and they won't lag behind what they planned to do. 7. Come and mix their language there, so that one does not understand the speech of the other. 8. The Lord scattered them from there over the whole earth; and they stopped building the city. 9. Therefore, he was given a name: Babylon (course. A. Chechelnitsky). The Lord mixed the language of the whole earth there and from there the Lord scattered them throughout the whole earth" [21]. According to Chechelnitsky, there was a certain Primordial Biblical Babylon, the latitude of which could lie within the limit's characteristic of the oldest areoastronomical monuments (about 48-54? N) [7]. Babylon should be sought in the region of the Amur River - Sakhalin Island - the southern part of the Sea of Okhotsk through markers of oil and asphalt deposits. The scientist determines the geolocation of the biblical plain of Sennaar, where people came after the Flood of Noah, first on the lands adjacent to the basin of the Amur River, and then on to the Yellow River [7]. Chechelnitsky claims that the Greek word Egypt is a product of the late Phoenician word formation, and it is replaced by the words "Mizraim", "the land of Mizraim" in the Old Testament [7]. Due to the lack of the names of the pharaohs and information about the pyramids (as well as the words "pyramid"), the scientist comes to the conclusion that there is no Egyptian African in the Bible. However, there was his connection with Original Egypt Mizraim and this connection should be sought through the ancient route of the pharaohs to the Holy Pint at the Outskirts of the World, where the Garden of Eden was located, where the people of the patriarch Abraham came during the famine [7]. Moreover, it is where Dilmun coincides with the edge of the biblical Mizraim that you need to look for Assyria, and Babylonia, and Judea. According to the German geographer R. Henning, whom A. Chechelnitsky refers to, but does not agree with everything, the ancient route to Punt, where the Queen Hatshepsut equipped expeditions for gold, silver and myrrh up to 80 thousand measures, was a country of the Gods for Egypt [22]. The Phoenician seafarers were the first to master the difficult path to Punt. One expedition there could last from a year to two years and be interrupted for a century or even millennia. Due to extreme climatic changes, the route of this path was lost in the labyrinths of history but was perpetuated by the creation of the famous Deir al-Bahri temple [7]. The first finds of this part of the Theban complex were made by the French Egyptologist G. Maspero in 1881. The inscriptions of the temple were of interest to R. Henning, who studied the travels and sailors of the pre-Columbian period in the 1930s. A. Chechelnitsky believes that the campaign of Alexander the Great, who sought to reach the Limits of the world, should be considered precisely in the context of ancient transit. Indeed, the commander's cherished dream was the land not of modern tropical India, but of the coastal Extreme India (Ultima India) located in the Far East, near the Pacific Ocean and its gulf seas - Bering and Okhotsk [7].

Finally, the scientist transfers the Trojan War to the Far East as a war for the right to control the Pontic trade in gold and silver, denying this right to the Eastern Mediterranean, traditionally considered the region of this event [7]. The transferred toponyms, according to A. Chechelnitsky, are a consequence of the catastrophic pole shift of the Earth's rotation. This problem is one of the least studied, but gradually attracting the attention of modern scientists in connection with the actualization of the problems of climate change on Earth [15] and its central theme of cosmogenic shock (hereinafter referred to as CS). According to the theory of wave cosmogeonomy, before CS, Northwest America, Hudson's Bay were the region of the Earth's Pole of rotation (or the North Pole of the past). Since latitudinal circulation dominated the Earth's climate and there was no meridional axis of rotation, there was no alternation of seasons (summerwinter) and Alaska was in the zone of eternal spring. Cosmogenic Shock around 9500 BC radically changed the living conditions of man. Atlantis, which flourished in the era of global glaciation, died with its completion, since the Pole of Earth's rotation left the Hudson Strait, not only changing its orientation around the world, but also causing distortion of the whole picture of the past [6]. A striking example of this is the reconstruction by scientists of the East European platform for the period 360 million years ago, when the territory of present-day Moscow was near the equator and, accordingly, in Moscow it was not only hot, but also less favorable from the point of view of the radiation background [23].

Chechelnitsky substantiates the problem by translating biblical information into modern concepts, arguing that if before the campaign of Patriarch Abraham it was a time of transgression - the Flood, then after the campaign - the Great Exodus - regression of the Sea of Okhotsk lowering the level of its surface, giving rise to the theme of the Jordan River, not covered by Moses, and the promised land in Canaan, where Joshua managed to get. This information is rethought by Chechelnitsky based on the evidence of Herodotus, who doubted the existence of 
such a river, whose Hellenic name was not the Jordan, but Eridan, which flowed into the North Sea [7].

The scientist is convinced that the events of the global catastrophe in the volcanic region in the Far East are reflected in the Biblical Exodus, when the waters parted, the sea became land, and the sons of Israel went "in the middle of the sea by land: the waters were their wall on the right and left side" [21]. This Exodus happened in the country of Mizraim, in the Kamchatka region on the continent's continent and in the region from which the Promised Land - Canaan begins. The regression period became a new era, since the level of lowering of the Sea of Okhotsk reached catastrophic limits. When its bottom appeared, the Jordan River flowed over it, filled with fresh waters from the mountains. The Jordan River flowed into the Salt Sea - the deepwater part of the Sea of Okhotsk [7].

The revelation of John the Evangelist testifies to the advent of new times: "I saw a new heaven and a new earth, for the former heaven and the former earth were gone, and the sea was gone. I saw the holy city, the new Jerusalem..." [18]. According to Chechelnitsky, the events associated with the regression of the Sea of Okhotsk occurred during the time of Abraham and Moses [7]. The transcontinental Exodus, which occurred in the first half of $1 \mathrm{BC}$, was characterized by several waves of migration when the continent began to colonize new lands in the Middle East and Europe from Continent PraRodina in the Far East.

\section{RESULTS}

Analyzing an extensive set of data from various sciences, the scientist formulates and confirms a number of hypotheses. Firstly, the studied ancient history is the socalled Displaced History. Secondly, this story was created in the format of Transferred place names, therefore, Real Geography, lost in the darkness of centuries and forgotten from the 1st millennium BC, needs to be restored. Thirdly, the so-called Limits of the World - the Far East, including North-East Siberia, Chukotka, Kamchatka, and Alaska or the ancestral continent in the broad sense, which should be considered the location of Atlantis, should be considered the true Homeland of Asian Europeans and the localization of historical events.

It seems that the scientist's logic and the introduction of the concepts "Relocated History", "Transferred Toponyms", "Real Geography", "The Limits of the World - Far East" into scientific circulation not only destroy the stereotypes of historical knowledge, but completely change the methodology of its construction, based on concepts of the Wave Universe, Wave Astrodynamics and Cosmogeonomy [24-28]. These findings are the result of an interdisciplinary discourse that raises one of the pressing problems of our time, called by A. Chechelnitsky "Cosmos-Earth-Man". This topic radically changes the view, both on the history of the Ancient East and the
Ancient World as a whole, substantially correcting modern ideas about the Prehistory of mankind.

\section{DISCUSSION}

The above theses of A. Chechelnitsky convincingly show that the problem he is considering is debatable from the name and concept to argumentation and conclusions. This makes the scientist's position extremely vulnerable compared with the authors of the history of the Ancient World, created by its authorities on the basis of "happily preserved evidence and documents, subsequently supplemented by archeology data ..." [7]. However, the analysis of conventional science leads astrophysicists to the firm conviction that not everything in the traditional interpretation of ancient history can be accepted as an undeniable truth, and therefore "we will not only have to accept that the kingdom of Sargon of Akkad, the state of the Old Babylonian, Cassite periods, Assyrian, The Chaldean kingdoms, their Metropolises were indeed located in the Middle East, but also provide convincing archaeological evidence for this" [7]. A. Chechelnitsky believes that today archaeologists should answer the following questions: 1 . Where are the cultural layers of the Middle East Babylon of the Hammurabi era or why the excavations begun by Koldeveey do not continue? 2 . Where are the traces of the 1st Jerusalem Temple of Solomon in the Middle East, which have archaeological evidence of the Second Temple? [7]. However, in order to answer them, professionals must begin this conversation. The detached attitude of the academic community towards a scientist who is critically analyzing established ideas was understandable in Soviet times. However, today's disregard for the problems raised by the researcher as, in fact, the works of A. Chechelnitsky, causes sincere regret. Meanwhile, reality is already pushing for a more careful study of issues of ancient history, contributing to an understanding of modern problems. Indeed, following the well-known biblical maxim, there is nothing new under the sun: "what was, it will be, and what was done, it will be done" [21].

Raising the question of an alternative understanding of history, A. Chechelnitsky proceeds from the importance of understanding the role of climate in history. The study of specific events, such as the death of Atlantis or Hyperborea, directly related to natural phenomena, shows how the geographic environment is transformed from a narrative narrative into a historical factor, and the question of the actual location of once existing continents becomes a significant scientific problem. It should be noted that the topic of deceased civilizations has been the subject of scientific debate for many centuries, starting with Plato, but has gone to the periphery of scientific knowledge since the nineteenth century. This is a topic studied by enthusiastic scientists, in fact, has not been developed, because, as Ortega y Gasset rightly believes, the process of crowding out a holistic culture in people from this time 
began, which eventually led to the emergence of this type of scientist, "which of the entire body of knowledge necessary to rise slightly above the average level, knows one thing - the only discipline ..." [29].

This situation, under the strict scientific conditions of the positivistic paradigm of the 20th century, left the historian no chance to get out of it. Everything that was not confirmed by the sum of artifacts and written evidence related to pseudoscience or to marginal research, considered speculative, significantly deviating from recognized theories. Accusations of academic marginality in Soviet historiography were tantamount to ostracism. It is believed that, for this reason, it was not the historian who dealt with this problem at all, but the physicist, who challenged the narrow specialization and formalization of research tools, relied on the complexity of the methods of studying history in the direction of interdisciplinarity to pose new questions and obtain fundamentally new results. In fact, why does the Old Testament not contain information about African Egypt? Finally, why is the concept of East divided into Near and Far?

Of course, the archaeologist A.V. Artsikhovsky is right a thousand times, noting that a historical phenomenon that left no trace in the archive or in the annals always remains in the ground, and the archaeologist's job is to find it [30]. After all, it is difficult to object to A. Chechelnitsky, who believed that until the time of excavation came, you can do mental archeology, search for the necessary information and, possibly, evidence in myths and languages that have come down to us. One can only regret the enormous harm to science caused by the closedness of the Soviet research laboratory, which did not allow A. Chechelnitsky, who developed the ideas of constructive paleolinguistics, to talk, and maybe enter into a discussion with his compatriot and contemporary Vyacheslav Ivanov - the largest Soviet linguist, semiotics and an anthropologist, author of the "theory of the main myth", as well as with the outstanding Soviet physicist S.P. Kapitsa, who studied the demographic problems of our time through the prism of ancient history [31]. Chechelnitsky was "a single warrior in the field", who asserted with enviable consistency that "a purely humanitarian approach alone cannot completely solve the fundamental problems of history", that the lack of interdisciplinarity strengthens the tendency to complicate historical methods of analysis, which inevitably leads to further formalization tools that reduce the effectiveness of the study [7].

\section{CONCLUSION}

All questions of the Prehistory of mankind raised by A.M. Chechelnitsky breaks the usual picture of the source of history and builds an interpretation algorithm of understanding, highlighting the incompleteness, and sometimes the inconsistency of knowledge. The problem of the transferred toponyms, hydronyms, ethnonyms is a serious clue to revising the established ideas about the source of history and to begin domestic interdisciplinary studies of the Far Eastern region, which is important for understanding the origins of history from the perspective of global tectonic changes on the planet before the Flood and after glaciation. The problem of the Far East as the Prehistory of mankind is a challenge to historical science and a serious educational problem [32]. In fact, A. Chechelnitsky proposed the idea of new knowledge based on the fundamental transformation of thinking, creating a new worldview of modern man, the pivotal support of which is the balance of relations between nature and man. However, considerable efforts will be required to solve it, aimed primarily at overcoming the vices of the modern worldview, as a product of the modern era with its "philosophical errors" - reductionist thinking and fragmentation of knowledge. Astrophysicist A. Chechelnitsky not only showed what integral thinking is and how, with its help, "a genuine understanding of the fundamental reality" is achieved - the only justification for scientific work. The scientist proceeded from the need to understand the importance of coinciding the boundaries of research and morality, that the tendency to more and more fragmented knowledge is immoral. Developing an alternative history, the scientist, in fact, anticipated the idea of an alternative philosophy of the "new Enlightenment", proclaimed by the participants of the Club of Rome [33]. It does not have a "natural right of the present before the past" (R. Bart), a postmodern right of the past over the present, but only a balance that provides the meaning of the object "existing in itself", both not deforming and not deformed by the idea introduced into it.

\section{REFERENCES}

[1] D. Christian, The Return of Universal History, History and Theory. Special Issue: History and Theory: The Next Fifty Years 49(2) (2010) 6-27.

[2] I. Saveleva, Historical science in the 21 st century. Keyword. Map of modern historiographical innovations. The beginning of the century through the eyes of a professional historian, Available at: http://gefter.ru/archive/22548.

[3] V. Pokrovsky, The Big Bang, which was not, Independent newspaper, May 19, 2004.

[4] A. Comte-Sponville, Scientism (Scientisme). Philosophical dictionary, LLC Publishing house "ETERNA", 2012.

[5] Books from the library of Albert Mikhailovich Chechelnitsky, Available at: http://lib.unidubna.ru/biblweb/search/rubrsearch_chech .asp? ID $=1 \&$ allcount $=81 \& \mathrm{dbeg}=81$. 
[6] A.M. Chechelnitsky, Plato's challenge: Atlantida Incognita, TERRA Book Club, 2004.

[7] A.M. Chechelnitsky, Prehistory begins at the Outskirts of the World, TERRA Book Club, 2005.

[8] M. Astvatsaturyan, Granit of science. Echo of Moscow, 22.12.2000, Available at: https://echo.msk.ru/programs/granit/2019.html.

[9] A. Derevyanko, Denisovsky man is known all over the world. News of Siberian science, Available at: http://www.sib-science.info/ru/institutes/derevyanko0510 .

[10] In the top ten! The most important scientific achievements of 2017 were named, Search 1-2 (2018).

[11] Saved Beringia. Search 3 (2018).

[12] D.M. Hopkins, The Bering Land Bridge, Stanford University Press, 1967.

[13] D.M. Hopkins, The history of sea level in Beringia over the past 250,000 years. Beringia in the Cenozoic, 1976.

[14] D.M. Hopkins, J.V. Matthews, C.E. Schweger, S.B. Young, Paleoecology of Beringia, Academic Press, 1982.

[15] The story in the ice. Antarctica tells about the Earth's past, Search 9 (2018).

[16] S.S. Kramer, The First Civilization on Earth, CJSC Centerpolygraph, 2002.

[17] S.N. Kramer, The story begins in Sumer, Book on Demand, 2012.

[18] The New Testament. Modern Russian translation, Russian Bible Society, 2017.

[19] Strabo. Geography in 17 books, Ladomir, 1994.

[20] J. Bibby, In search of Dilmun, Nauka, 1984.

[21] The Bible. The book of Holy Scripture of the old and New Testaments is canonical.

[22] R. Henning, The unknown land, Publishing house of foreign literature1-2 (1961) 21-32, Available at: http://annales.info/other/hennig/.

[23] V. Yanchilin, Messages in intrusions. Frozen lava will tell about the history of the Earth, Search 10 (2018).
[24] A.M. Chechelnitsky, Hot Points of the Wave Universe Concept: New World of Megaquantization, in: Proceedings of International Conference "Hot Points in Astrophysics", Dubna, Russia, August 22-26, 2000, Available at:

http://arXiv.org/abs/physics/0102036.

[25] A.M. Chechelnitsky, Horizons of the Wave Universe Concept: from Neutrino - to Quasars, Report COSPAR 02-A-00056, H0.2-E0.2-0025-02 to the 34th COSPAR Scientific Assembly - World Space Congress, Houston, Texas, USA, October 10-19, 2002.

[26] A.M. Chechelnitsky, Heritage of the Global Ancient Civilization: Discrete Structure, Great Belt of Megalithic Sites (Observatories), Report to the SEAC (European Society of Astronomy and Culture) 2002 Meeting, Tartu, Estonia, August 27-30, 2002.

[27] A.M. Chechelnitsky, Hubble Constant or Hubble Variable H: Why Is Not the "Exact" H Discovered? In: Astronomy, Cosmology and Fundamental Physics, Proceedings of the ESO/CERN/ESA Simposium Held in Garching, Germany, March 4-7, 2002, Springer, pp. 429-431.

[28] A.M. Chechelnitsky, Cosmological Alternatives: (Mega) Wave Universe Concept, Alpha Constant, Hubble H Variable, Report to CAPP 2003, Workshop on Cosmology and Particle Physics, CERN, Geneva, Switzerland, June 12-17, 2003.

[29] J. Ortega y Gasset, The uprising of the masses, AST, 2002.

[30] L. Lyubimov, Art of the Ancient World, Education, 1980.

[31] S. Kapitsa, Paradoxes of growth: Laws of human development, Alpina non-fiction, 2010.

[32] I.A. Gataullina, Pre-et-protohistory as world outlook basis of engineering ethics, in: The European Proceedings of Social \& Behavioural Sciences EpSBS, RRI, 2016, International Conference «Responsible Research and Innovation», pp. 254-261.

[33] E. von Weizsaecker, A. Wijkman, Come On! Capitalism, Short-termism, Population and the Destruction of the Planet, Springer, 2018, Report of the Club of Rome 2018, Review of Professor A.

Chumakov, Available at: http://ecoparlament.ru/d/828816/d/dokdad_rimskogo_k luba-2018.pdf. 